\title{
Lessons from a theory of change-driven evaluation of a global mental health funding portfolio
}

\author{
G. Miguel Esponda ${ }^{1,2^{*}+}$, G. K. Ryan ${ }^{3 \dagger}$, G. Lockwood Estrin' ${ }^{4}$, S. Usmani ${ }^{5}$, L. Lee ${ }^{6}$, J. Murphy ${ }^{7}$, O. Qureshi ${ }^{3}$,T. Endale ${ }^{8}$, \\ M. Regan ${ }^{9}$, J. Eaton $^{3,10+}$ and M. De Silva ${ }^{11+}$
}

\begin{abstract}
Background: Given the underinvestment in global mental health to-date, it is important to consider how best to maximize the impact of existing investments. Theory of Change (ToC) is increasingly attracting the interest of funders seeking to evaluate their own impact. This is one of four papers investigating Grand Challenges Canada's (GCC's) first global mental health research funding portfolio (2012-2016) using a ToC-driven approach.

Methods: A portfolio-level ToC map was developed through a collaborative process involving GCC grantees and other key stakeholders. Proposed ToC indicators were harmonised with GCC's pre-existing Results-based Management and Accountability Framework to produce a "Core Metrics Framework" of 23 indicators linked to 17 outcomes of the ToC map. For each indicator relevant to their project, the grantee was asked to set a target prior to the start of implementation, then report results at six-month intervals. We used the latest available dataset from all 56 projects in GCC's global mental health funding portfolio to produce a descriptive analysis of projects' characteristics and outcomes related to delivery.

Results: 12,999 people were trained to provide services, the majority of whom were lay or other non-specialist health workers. Most projects exceeded their training targets for capacity-building, except for those training lay health workers. Of the 321,933 people screened by GCC-funded projects, 162,915 received treatment. Most projects focused on more than one disorder and exceeded all their targets for screening, diagnosis and treatment. Fewer people than intended were screened for common mental disorders and epilepsy (60\% and 54\%, respectively), but many more were diagnosed and treated than originally proposed ( $148 \%$ and $174 \%$, respectively). In contrast, the three projects that focused on perinatal depression exceeded screening and diagnosis targets, but only treated $43 \%$ of their intended target.

Conclusions: Under- or over-achievement of targets may reflect operational challenges such as high staff turnover, or challenges in setting appropriate targets, for example due to insufficient epidemiological evidence. Differences in delivery outcomes when disaggregated by disorder suggest that these challenges are not universal. We caution implementers, funders and evaluators from taking a one-size-fits all approach and make several recommendations for how to facilitate more in-depth, multi-method evaluation of impact using portfolio-level ToC.
\end{abstract}

\footnotetext{
*Correspondence: georgina.miguel_esponda@kcl.ac.uk

${ }^{\dagger} \mathrm{G}$. Miguel Esponda and G. K. Ryan—Joint first authors

${ }^{\dagger}$ J. Eaton and M. De Silva-Joint final authors

${ }^{1}$ Health Service and Population Research Department, Institute

of Psychiatry, Psychology and Neuroscience, King's College London, 16 De

Crespigny Park, Camberwell, London SE5 8AB, UK

Full list of author information is available at the end of the article
}

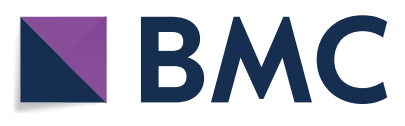

(c) The Author(s) 2021. This article is licensed under a Creative Commons Attribution 4.0 International License, which permits use, sharing, adaptation, distribution and reproduction in any medium or format, as long as you give appropriate credit to the original author(s) and the source, provide a link to the Creative Commons licence, and indicate if changes were made. The images or other third party material in this article are included in the article's Creative Commons licence, unless indicated otherwise in a credit line to the material. If material is not included in the article's Creative Commons licence and your intended use is not permitted by statutory regulation or exceeds the permitted use, you will need to obtain permission directly from the copyright holder. To view a copy of this licence, visit http://creativeco mmons.org/licenses/by/4.0/. The Creative Commons Public Domain Dedication waiver (http://creativecommons.org/publicdomain/ zero/1.0/) applies to the data made available in this article, unless otherwise stated in a credit line to the data. 
Keywords: Global mental health, Theory of change, Implementation

\section{Background}

\section{Investing in global mental health}

Despite growing recognition of the importance of mental health to political and development agendas [1], median government expenditure on mental health ranges from just 0.02 United States dollars (USD) per capita in lowincome countries to 2.62 USD in upper middle-income countries [2]. In sub-Saharan Africa, for example, this amounts to less than $1 \%$ of countries' overall health budgets. Meanwhile, only $0.4 \%$ of all overseas development assistance for health is allocated to mental health [3]. This is in stark contrast to the high prevalence of mental, neurological and substance use (MNS) disorders, which may contribute up to $13.03 \%$ of the global burden of disease [4].

Redressing these imbalances by increasing local and international investment in mental health has been a key priority for the global mental health movement since its inception [5]. Research efforts have focused on garnering evidence for investment, for example by demonstrating the cost-effectiveness of mental health interventions that increase access to care in low-resource settings. Many interventions have proven successful in improving health and functional outcomes, and have even garnered international attention in the media [6] and at highprofile events for policy-makers $[7,8]$ and other funders [9]. Yet investment in mental health remains stubbornly low, even when compared to other health sectors. To illustrate: from 2010-2016 nearly half of all disability assistance for health was spent on the control of sexuallytransmitted diseases such as HIV/AIDS, while HIV/AIDS was responsible for less than $5 \%$ of the global burden of disease [10].

Given the relative underinvestment in global mental health to-date, it is important to consider how best to maximize the impact of existing investments, and funders often seek evidence of value for money to support further funding decisions. Numerous priority-setting exercises have been undertaken to ensure that the limited resources available for mental health in low- and middle-income countries (LMICs) are used efficiently to target strategic issues, particularly in terms of research [5, 11-14]. Less attention has been paid to ensuring that funding made available for global mental health is used to maximum effect. Theory of Change (ToC), which in recent years has become a popular tool for the design and evaluation of complex interventions in global mental health [15], is increasingly attracting the interest of funders seeking to evaluate their own impact [16-18]. This is one of four papers investigating Grand Challenges Canada's (GCC's) first global mental health research funding portfolio, using a ToC-driven approach.

\section{Evaluating a global mental health funding portfolio}

Launched in 2010, GCC is a non-profit organisation funded by the Canadian Government and other partners. It is one of relatively few development organisations that has invested in a funding programme dedicated to global mental health. By 2016, GCC had committed \$28,232,030 CAD to 51 projects in its Global Mental Health Programme and leveraged an additional $\$ 1,297,946$ CAD in co-funding [19]. Funding was also made available to mental health projects via the GCC Stars in Global Health and Transition to Scale programmes (launched in 2010 and 2013, respectively). Together, these programmes created a pipeline granting innovators seed funding to demonstrate proof of concept, with the potential for further funding to support larger-scale intervention and implementation research.

This pipeline structure is consistent with GCC's commitment to "an evidence-based approach to development innovation" (Grand Challenges Canada, n.d.) and the nature of innovation seed funding more broadly, where potential for scale and wider population benefit are core to the investment model. Grantees must evidence the viability and transformative potential of their innovation at each stage of the pipeline before moving on to the next. Further, as a government-funded organisation, GCC must maintain transparency by demonstrating how taxpayer dollars have been used and to what ends. Consequently, GCC requires a high level of routine reporting from its grantees, collating process and outcome data across its Results-based Management and Accountability Framework (RMAF) and evaluating the success of its various funding portfolios in terms of 'number of lives improved' [19].

The result is a wealth of data available from grantees' earliest stages of seed funding - and in some cases through to scale-up-for a diverse portfolio of mental health projects carried out over a similar timespan via a single funder. This provides a unique opportunity for research and evaluation. For example, overarching questions related to human resources, case detection and accessibility of health care services can be examined 
across different projects that share these common intervention elements, providing a broad view of many of the key issues and practical challenges in improving mental health in LMIC settings.

In this paper, we share descriptive results of a quantitative analysis of the GCC portfolio's Core Metrics data, and examine the strengths and limitations of a ToCdriven approach to portfolio-level evaluation, for which there is very little practical guidance currently available [16]. Related papers by Endale et al. [21], Murphy et al. [22] and Qureshi et al. [23] in this series describe the qualitative components of this evaluation, with a focus on barriers and facilitators to successful implementation across three key areas: (i) stakeholder engagement; (ii) capacity building; and (iii) service delivery. Our aim is to harness and share learning from one of the biggest investments in global mental health to-date, relevant both to funders like GCC and to implementers working in the field.

\section{Methods}

We carried out a multi-method, ToC-driven evaluation of GCC's 2012-2016 global mental health investment portfolio. This portfolio consists of 56 mental health projects funded through the Global Mental Health and Transition to Scale programmes. Our objectives were:

1. To describe the characteristics of the mental health projects included in the GCC portfolio.

2. To assess the extent to which grantees achieved their pre-identified outcomes on a collective pathway of change.

3. To illustrate the use of a multi-method ToC-driven methodology as a means of synthesising key data and learning regarding the implementation of a diverse portfolio of projects.

4. To investigate, using qualitative methods, factors affecting implementation that may help or hinder progress along the pathway of change (reported elsewhere in this series).

\section{Evaluation framework \\ Portfolio-level theory of change}

From 2013 to 2016, GCC funded an innovator support platform called the Mental Health Innovation Network (MHIN, www.mhinnovation.net). MHIN is a collaboration between the Centre for Global Mental Health at the London School of Hygiene and Tropical Medicine (LSHTM) and the Department of Mental Health and Substance Abuse at the World Health Organization (WHO). One of the key services that MHIN provided to
GCC was assistance in portfolio-level monitoring and evaluation.

To evaluate the collective impact of mental health projects across GCC's funding programmes, researchers at MHIN proposed a ToC-driven approach. ToC is "a theory of how and why an initiative works", laying bare the causal pathway by which an initiative aims to achieve impact [18]. Often a ToC is depicted visually as a diagram and developed in consultation with key stakeholders, with additional benefits for consensus-building and communication [15, 24]. By assigning indicators to short-, medium- and long-term outcomes along the causal pathway, a $\mathrm{ToC}$ can be especially valuable as an evaluation framework. Pin-pointing where on this causal pathway an initiative fails to produce expected outcomes can help to "unpack the black box" of evaluation [25], distinguishing between "ideas that don't work" (theory failure) and "ideas that haven't been properly tested" (implementation failure) [26].

At the time of GCC's Global Mental Health Programme launch, ToC was already in use by international mental health research consortia like PRIME (PRogramme for Improving Mental hEalth care) [27]. Utilizing a combination of country-specific and overarching, cross-country ToC maps, PRIME demonstrated that it is possible to simultaneously monitor and evaluate necessarily heterogenous, complex interventions both at the individual country level and collectively across participating country sites. PRIME's Nepal site has also demonstrated that ToC can be used in combination with methods of qualitative comparative analysis (QCA) to identify which conditions are necessary and sufficient to bring about change [28].

In international development more broadly, $\mathrm{ToC}$ is increasingly being used by funders to plan, monitor and evaluate their portfolios $[17,18,25,29]$. A ToC can be empirically tested and amended iteratively to reflect new learning, providing a road-map for current and future investment $[18,25,29,30]$. Funders may be encouraged to develop an a priori $\mathrm{ToC}$ map before starting the selection process, to gauge how each potential applicant can contribute to the envisioned pathway of change [17, 25]. However, particularly in relatively young fields such as global mental health, grantees may have more specialist expertise and experience than their funders $[17,25]$. Under these circumstances, grantees can play an important role in defining the pathway by which they expect the funding they receive to help achieve the funders' desired impact [17, 25]. In the case of GCC, a ToC was developed through an iterative process involving grantees and representatives of the funding organisation, facilitated by experienced evaluators from the MHIN team at LSHTM. 


\section{Development of the theory of change}

An initial ToC workshop was held at a Grand Challenges Community Meeting in Rio de Janeiro, Brazil, in October 2013. A working statement of impact was agreed and outcomes were backward-mapped onto a ToC diagram (Appendix 1). Indicators were suggested for each outcome under a proposed ceiling of accountability, defined by De Silva et al. (2014, p. 5) as the level at which you "stop accepting responsibility for achieving those outcomes... often drawn between the impact and the long term outcome". Because only a very small proportion of GCC grantees would go on to receive funds for "Transition to Scale", this ceiling of accountability was drawn under "Scale-Up".

Grantees also received training and elective one-toone support to develop their own project-specific ToC diagrams. These were compared to the portfolio-level $\mathrm{ToC}$, which was then revised accordingly. Further adjustments were made upon review of grantees' 'Core Metrics' reporting (described below), again to ensure that the portfolio-level $\mathrm{ToC}$ adequately reflected the component projects. Revisions to the portfolio-level $\mathrm{ToC}$ were presented to grantees and representatives of the funding organisation during annual GCC meetings, for feedback. Final changes were made in April 2015, at which point the $\mathrm{ToC}$ was "locked" for evaluation (i.e., outcomes and indicators could no longer be changed without disrupting data collection, as described further below).

\section{Data collection}

As GCC already had a mandatory RMAF reporting system in place, proposed portfolio-level ToC indicators were adjusted where possible to align with existing indicators. The goal was to minimise the burden of reporting placed on grantees, while still collecting data against essential process and outcome indicators for monitoring and evaluation of the overall portfolio. The result was a Core Metrics Framework introduced in 2015, consisting of 23 indicators linked to the 17 outcomes of the ToC map (Appendix 1). These outcomes were grouped under four domains: project development $(\mathrm{n}=4)$, delivery $(n=6)$, evaluation $(n=3)$, and context $(n=4)$. For each indicator relevant to their project, the grantee was asked to set a target prior to the start of implementation, then report results (for example the number of people they expected to treat through the project). Reports were submitted by grantees to GCC and transferred to MHIN at six-month intervals for analysis.

\section{Analysis}

The quantitative analysis was conducted between November 2016 and March 2017. We used the latest available data from all GCC projects $(\mathrm{n}=56)$ related to delivery outcomes (Table 1). We used descriptive statistics to describe the projects' characteristics, results based on indicators and to compare projects' level of achievement in relation to their intended targets. All analyses were conducted using IBM SPSS Statistics (Version 25).

Our analysis plan was affected by several data limitations, despite numerous efforts to contact grantees both directly and via GCC to verify project data. First, large amounts of data were missing, mainly because not all outcomes were applicable to all projects. However, it was not always possible to differentiate between data that were missing due to irrelevance and data that were missing due to purposeful or accidental omission or inadequate monitoring and evaluation. Missing data was a particularly big issue for the project development outcomes. Second, given that many grantees did not report data on the outcomes of service users or other

Table 1 Summary of indicators for delivery outcomes

\begin{tabular}{|c|c|}
\hline Outcome & Indicator \\
\hline $\begin{array}{l}\text { 1. Adequate ongoing management, supervision and quality improvement } \\
\text { procedures in place }\end{array}$ & $\begin{array}{l}\text { Continuous quality improvement (CQI) mechanism in place (e.g. regular } \\
\text { supervision, repeat training, other } \mathrm{CQI} \text { methods) }\end{array}$ \\
\hline 2. Number of service providers (intermediaries) trained & $\begin{array}{l}\text { Numerator: Number of service providers (intermediaries) trained } \\
\text { Denominator: Target number of service providers (intermediaries) to be } \\
\text { trained }\end{array}$ \\
\hline 3. Target population (beneficiaries) with mental health disorders identified & $\begin{array}{l}\text { Numerator: Number of people in target population (beneficiaries) screened } \\
\text { and identified } \\
\text { Denominator: Target number of people to be screened and identified }\end{array}$ \\
\hline 4. Health promotion innovations are accessible & $\begin{array}{l}\text { Numerator: Proportion of target population with access to innovation } \\
\text { medium (e.g. television, radio, internet) } \\
\text { Denominator: Expected proportion of target population with access to the } \\
\text { innovation medium (e.g. television, radio, internet) }\end{array}$ \\
\hline $\begin{array}{l}\text { 5. Target population (beneficiaries) receive integrated innovation as } \\
\text { intended }\end{array}$ & $\begin{array}{l}\text { Numerator: Number of people (beneficiaries) who received innovation } \\
\text { (disaggregated by diagnosis, level of care, year of project etc.) } \\
\text { Denominator: Target number of people to receive innovation }\end{array}$ \\
\hline
\end{tabular}


beneficiaries (e.g. family members) within the GCCfunded timeframe, most of the data collected against the Core Metrics Framework were related to implementation. Some grantees never completed their evaluations of beneficiaries' outcomes, and others were protective of their results during the long embargo period for publication in peer-reviewed journals. Third, our quantitative approach was ill-fitted to some of the more heterogeneous outcomes that proved difficult to categorise (e.g. outcomes related to context) and were better described through rich qualitative descriptions. Due to these challenges, we limited our quantitative analysis to delivery outcomes (Table 1).

In the analysis of delivery data, there were several instances when disaggregated data was not provided by grantees (e.g. for types of providers trained or types of diagnoses screened, diagnosed and treated). Regarding types of diagnoses, several projects targeted more than one disorder therefore in the absence of disaggregated data it was impossible to know the number of people that had been screened, diagnosed or treated in each category. We only present disaggregated data when available and report the number for which disaggregated data is not available.

\section{Results}

\section{Project characteristics}

The global mental health investment portfolio consisted of 56 projects from the Global Mental Health and Transition to Scale programmes. The characteristics of these projects and the subsample that participated in the qualitative component are summarised in Table 2 . Thirty-five projects (62\%) targeted more than one disorder, life stage, population group and/or project component. Common mental disorders were the most frequently targeted (52\%), followed by behavioural and emotional disorders (39\%). The number of projects targeting adults (37\%) was similar to the number targeting children and young adolescents (41\%) and women (39\%). The highest proportion of projects were located in Africa (45\%), followed by South Asia (27\%). Most projects carried out capacity building activities (95\%), treatment, care and rehabilitation $(88 \%)$, and stakeholder engagement (79\%).

\section{Capacity building (outcomes 1 and 2 )}

Capacity building activities included the delivery of training $(\mathrm{n}=54)$ and use of quality assurance mechanisms $(\mathrm{n}=49)$ (Table 3). Most training activities were fully or partially delivered by specialists through multiple faceto-face sessions. Two projects did not report the number of people they trained; however, the remaining 52 trained a total of 12,999 people, the majority of whom were lay workers and other non-specialist health workers [Fig. 1].
The number of participants in quality assurance activities was not systematically reported. Supervision was the most frequently used quality assurance mechanism, which in most cases was delivered on a weekly basis and by specialists or project staff.

Over half of projects trained health workers, including specialist, non-specialist or lay health workers, to deliver mental health services (Fig. 1). Other providers trained to deliver mental health services included school staff and spiritual or traditional healers, with school staff being the third most commonly trained type of provider. Training targets were exceeded for all types of providers, except for lay health workers. However, even in this case almost $90 \%$ of the intended lay health workers were trained. For other provider types, projects exceeded their training targets by more than a third. For example, the number of specialists trained was twice as large as originally intended.

\section{Delivery (Outcomes 3-5)}

Services delivered included screening and diagnosis $(\mathrm{n}=46)$, treatment $(\mathrm{n}=49)$ and mental health promotion and awareness $(n=22)$. Table 4 presents the characteristics of the services delivered by all projects, and Figs. 2, 3 and 4 present the total number of people who were screened, diagnosed and who accessed treatment, as well as the extent to which targets set by projects were achie ved.

Screenings were most commonly conducted at the community level (45\%) using paper-based tools (67\%). Five projects that conducted screenings did not report outcome data, however the remaining 41 projects reported screening a total of 321,933 people, primarily for common mental disorders. The three projects with the highest number of people screened used technological solutions for screening and reported screening between 30,000 to 45,000 people. Forty-five projects reported diagnosing 75,208 people, $51 \%$ of which were diagnosed with a common mental disorder.

Most treatment interventions provided by projects consisted of talk-based (69\%) and psychosocial interventions $(71 \%)$ delivered at the community level $(76 \%)$ by non-specialist health workers $(67 \%)$ or lay health workers (55\%). All 49 projects that included a treatment intervention reported the number who accessed treatment. A total of 162,915 people received treatment, nearly half receiving treatment for common mental disorders.

Most projects focused on more than one disorder and exceeded all their targets for every disorder (Figs. 2, 3 and 4). Fewer people than intended were screened for common mental disorders and epilepsy (i.e. $60 \%$ and $54 \%$, respectively), but many more were diagnosed (i.e. $211 \%$ and $147 \%$, respectively) and treated (i.e. $174 \%$ and $148 \%$, 
Table 2 General characteristics of included GCC mental health projects

\begin{tabular}{|c|c|c|}
\hline & $\begin{array}{l}\text { Core Metrics analysis }(n=56) \\
N(\% \text { of total) }\end{array}$ & $\begin{array}{l}\text { Qualitative } \\
\text { study }(n=29) \\
N(\%)\end{array}$ \\
\hline \multicolumn{3}{|l|}{ Target disorder } \\
\hline Common mental disorders & $29(52)$ & $16(55)$ \\
\hline Behavioural and emotional disorders & $22(39)$ & $13(45)$ \\
\hline Epilepsy and seizures & $15(27)$ & $5(17)$ \\
\hline Severe mental disorders & $12(21)$ & $6(21)$ \\
\hline Trauma and PTSD & $12(21)$ & $7(24)$ \\
\hline Suicide and self-harm & $11(20)$ & $7(24)$ \\
\hline Developmental disorders & $10(18)$ & $7(24)$ \\
\hline Alcohol and substance use disorders & $9(16)$ & $5(17)$ \\
\hline Dementia & $3(5)$ & $2(7)$ \\
\hline All & $6(11)$ & $3(10)$ \\
\hline \multicolumn{3}{|l|}{ Target life stage } \\
\hline Newborns & $5(9)$ & $2(7)$ \\
\hline Infants, children and early adolescents & $23(41)$ & $14(48)$ \\
\hline Adults (including young adults) & $21(37)$ & $13(45)$ \\
\hline Elderly & $9(16)$ & $6(21)$ \\
\hline \multicolumn{3}{|l|}{ Target population } \\
\hline Women & $22(39)$ & $9(31)$ \\
\hline Vulnerable groups (e.g. conflict affected populations) & $16(29)$ & $10(34)$ \\
\hline General population (any life stage) & $12(21)$ & $12(41)$ \\
\hline \multicolumn{3}{|l|}{ Region } \\
\hline Africa & $25(45)$ & $10(35)$ \\
\hline South Asia & $15(27)$ & $11(38)$ \\
\hline Central America and the Caribbean & $9(16)$ & $4(14)$ \\
\hline South East Asia & $9(16)$ & $3(10)$ \\
\hline South America & $6(11)$ & $1(3)$ \\
\hline \multicolumn{3}{|l|}{ Project components } \\
\hline Capacity building & $54(95)$ & $23(79)$ \\
\hline Detection, treatment, care and rehabilitation & $49(88)$ & $22(76)$ \\
\hline Stakeholder engagement & $44(79)$ & $12(41)$ \\
\hline Promotion and awareness & $22(39)$ & $18(62)$ \\
\hline
\end{tabular}

respectively) for these disorders than originally expected. All targets for substance use disorders, developmental disorders and dementia were exceeded, although it is worth noting that some of projects set very low targets for these disorders (e.g. dementia). In the case of perinatal depression, despite exceeding screening and diagnosis targets, projects only provided treatment to $43 \%$ of their intended target for this disorder.

\section{Discussion}

This paper describes a diverse sample of mental health projects funded by GCC. Our findings highlight the utility of a ToC-driven process to define and map portfoliolevel indicators across a pathway of change, to identify common outcomes, guide evaluation of challenges and drivers of successful implementation and identify knowledge gaps. These gaps were explored further using qualitative methods, the results of which are reported elsewhere in this series and referenced in our discussion below. Recommendations to funders and implementers involved in similar evaluation processes are summarised in Box 1.

\section{Capacity building and service delivery}

Most projects exceeded their training targets for capacity-building. It is likely that unexpected staff turnover forced projects to train more service providers than initially planned. Retention emerged as a key barrier in the 
Table 3 General characteristics of training and quality assurance mechanisms used by GCC projects

\begin{tabular}{|c|c|}
\hline Type of training & 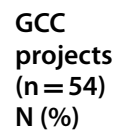 \\
\hline Face-to-face & $38(70)$ \\
\hline Online & $2(4)$ \\
\hline Face-to-face and online & $14(26)$ \\
\hline \multicolumn{2}{|l|}{ Frequency of training } \\
\hline Multiple sessions (range $2-10$ sessions) & $50(92)$ \\
\hline One session & $4(8)$ \\
\hline \multicolumn{2}{|l|}{ Training provider } \\
\hline Specialists & $35(65)$ \\
\hline Non-specialists & $2(4)$ \\
\hline Specialists and non-specialists & $8(15)$ \\
\hline Type of quality assurance mechanism & $\begin{array}{l}\text { GCC } \\
\text { projects } \\
(n=49) \\
N(\%)\end{array}$ \\
\hline Supervision & $46(94)$ \\
\hline Refresher training & $20(41)$ \\
\hline Information system & $8(16)$ \\
\hline Evaluation & $7(14)$ \\
\hline Programme manager & $6(12)$ \\
\hline \multicolumn{2}{|l|}{ Frequency of contact for quality assurance } \\
\hline Weekly & $27(55)$ \\
\hline Monthly & $13(27)$ \\
\hline Every few months & $7(14)$ \\
\hline \multicolumn{2}{|l|}{ Quality assurance provider } \\
\hline Project staff & $37(76)$ \\
\hline Specialists & $35(71)$ \\
\hline Non-specialists & $16(33)$ \\
\hline Service users or carers & $2(4)$ \\
\hline
\end{tabular}

qualitative component of our research, particularly during the training and service delivery phases of project implementation [21]. Previous studies have reported high turnover among health workers to be a common and significant challenge to implementation, especially for time-limited projects [31]. The fact that lay health workers were the only type of provider for which training targets were not exceeded could perhaps be a reflection of comparatively low turnover in this cadre, as described by some interviewees who suggested that participation in the project offered valued opportunities for lay people to advance their careers in contexts of high unemployment [21].

More than $80 \%$ of projects included screening and treatment components, whereas only around 40\% included mental health promotion and awareness-raising activities. Improvements in service delivery benefit the population in need of treatment, but further action on mental health promotion and awareness is important for the wider population at risk. In particular, investment in promotion and awareness is needed to strengthen early identification in young people and can be cost-effective, with potentially high returns [32]. However, activities that increase detection of mental disorders should be coupled with efforts to strengthen mental health systems, to avoid generating demand that cannot be safely and effectively met by existing services.

Over- or under-estimating the level of demand for services was a commonly faced barrier to successful delivery for grantees [23]. Reliance on isolated prevalence estimates [33], lack of appropriate epidemiological statistics on population mental health [34], limited understanding 


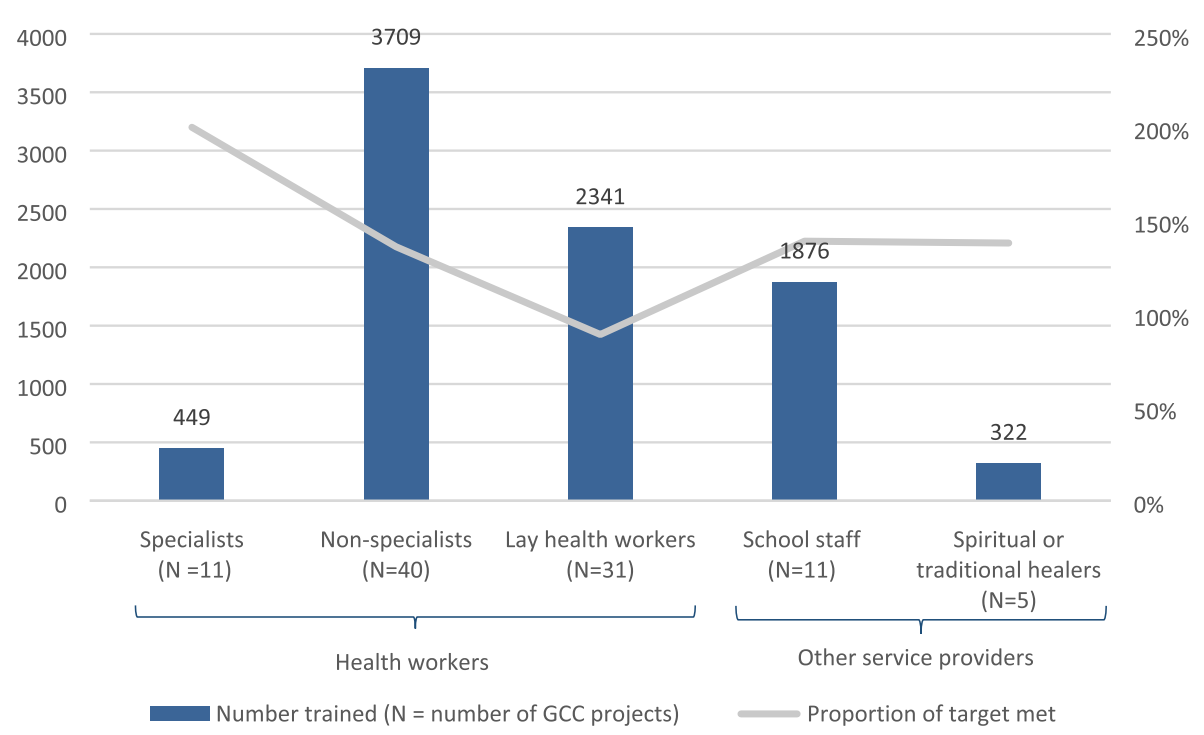

Fig. 1 Number of providers trained in each cadre. *Missing disaggregated data for 4,302 people who received training

of the attitudes on help seeking for mental health [35], fragmented routine data around existing service use [36], and lack of validation of screening tools [37] could all be contributing factors. Screening targets for common mental disorders and epilepsy were the most likely to be underachieved but treatment and diagnosis targets for these disorders were more likely to be overachieved. Screening, diagnosis and treatment targets for substance use disorders, dementia and developmental disorders were overachieved and projects targeting perinatal depression overachieved screening and diagnosis targets but underachieved treatment targets.

We can take away from these differences in delivery outcomes across various MNS disorders three possible lessons. First is the need for different activities and interventions to engage and treat people with different MNS disorders. It is likely that a one-size-fits-all approach will leave certain groups underserved. Second is that there may be greater knowledge gaps for some disorders, making it more difficult to accurately estimate and plan for service delivery. Funders may need to make special considerations for projects targeting disorders that have been historically ignored; for example, by offering longer timelines and additional resources to carry out formative research before setting targets. Third is that the need for special consideration also extends to our own analysis. While we did disaggregate quantitative data on delivery outcomes by disorder, any conclusions we might seek to draw from this evaluation at the portfolio level will be heavily skewed toward common mental disorders, which were those most frequently targeted by GCC projects.

Bearing this final challenge in mind, it is promising to note that GCC's investment has resulted in large numbers of human resources trained in mental health, of people screened for mental health conditions, and of people accessing care in LMICs. This offers hope for the possibility of scaling up mental health care in low-resource settings around the world. However, our analysis does not answer the all-important question of whether and how this care actually benefits the individuals, services and communities involved. Answering this more difficult question requires overcoming some of the limitations described below and in our recommendations for portfolio-level analysis [Box 1].

\section{Strengths and limitations}

The use of a multi-method ToC approach was a strength of this research. ToC workshops can facilitate the involvement of multiple stakeholder groups in the mapping process [24]. In the case of GCC's portfolio-level ToC, this process allowed for the identification of indicators at each step of a collective pathway of changeincluding indicators that were not already accounted for in GCC's pre-existing project evaluation framework (RMAF). Data collected against these indicators allowed for the aggregation of output data-such as number of people diagnosed and treated-across projects, helping GCC to communicate the performance of its portfolio to 
Table 4 General characteristics of screening, treatment and promotion interventions delivered by GCC projects

\begin{tabular}{|c|c|}
\hline Type of screening methods & $\begin{array}{l}\begin{array}{l}\mathrm{GCC} \\
\text { projects } \\
(\mathrm{n}=46)\end{array} \\
\mathrm{N}(\%)\end{array}$ \\
\hline Paper-based & $31(67)$ \\
\hline mHealth & $5(11)$ \\
\hline Paper-based and mHealth & $10(22)$ \\
\hline \multicolumn{2}{|l|}{ Screening setting } \\
\hline Community & $21(45)$ \\
\hline Clinic & $12(27)$ \\
\hline School & $4(8)$ \\
\hline Multiple settings & $9(20)$ \\
\hline Type of treatments delivered & $\begin{array}{l}\text { GCC } \\
\text { projects } \\
(n=49) \\
N(\%)\end{array}$ \\
\hline Psychosocial interventions & $35(71)$ \\
\hline Talk-based interventions & $34(69)$ \\
\hline Pharmacological treatment & $18(37)$ \\
\hline \multicolumn{2}{|l|}{ Setting of treatment delivery } \\
\hline Community & $37(76)$ \\
\hline Primary care clinics & $29(59)$ \\
\hline Home & $16(33)$ \\
\hline Specialist clinics & $13(26)$ \\
\hline School & $8(16)$ \\
\hline Workplace & $4(8)$ \\
\hline \multicolumn{2}{|l|}{ Treatment provider } \\
\hline Non-specialist health workers & $33(67)$ \\
\hline Lay health workers & $27(55)$ \\
\hline Specialist health workers & $24(49)$ \\
\hline School staff & $5(10)$ \\
\hline Spiritual or traditional healers & $4(8)$ \\
\hline Type of promotional activities & $\begin{array}{l}\begin{array}{l}\mathrm{GCC} \\
\text { projects } \\
(\mathrm{n}=22) \\
\mathrm{N}(\%)\end{array} \\
\end{array}$ \\
\hline Face-to-face activities & $19(86)$ \\
\hline Distribution of printed materials & $16(73)$ \\
\hline Media & $9(41)$ \\
\hline Online/mHealth & $3(14)$ \\
\hline
\end{tabular}

key stakeholders [38]. The ToC mapping also helped to pinpoint where on the pathway grantees commonly experienced challenges, which were explored further through qualitative analysis (see companion papers in this series for detailed examples).
However, some components of the $\mathrm{ToC}$ pathway proved difficult to measure either quantitatively or through sufficiently standardised qualitative methods (e.g. summative content analysis) to enable aggregation. For example, during interviews both context and stakeholder 

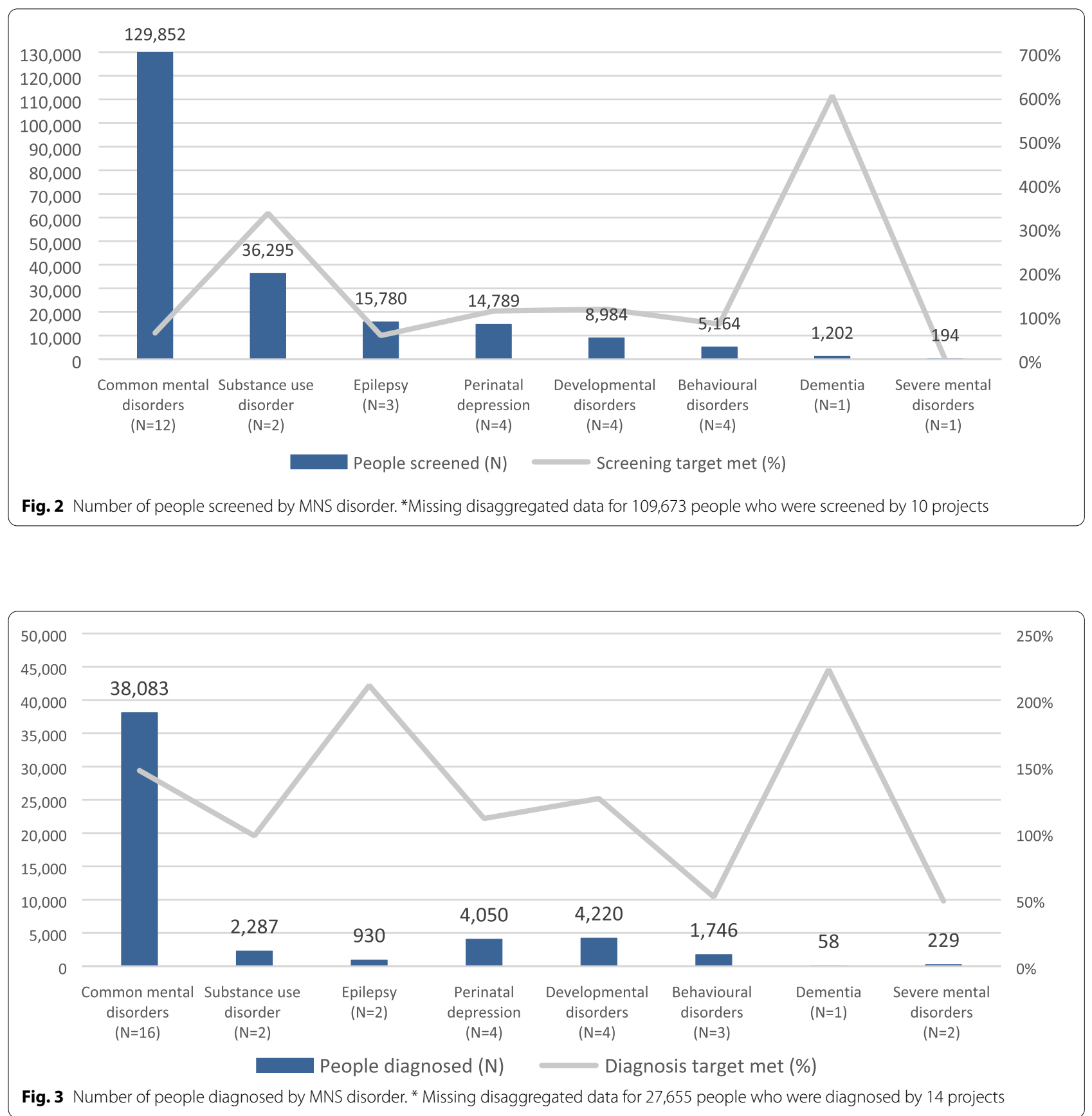

engagement were identified as highly relevant to the process of implementation, and this important finding would have been missed if we had relied solely on quantitative data. Grantees described stakeholder engagement as one of the key factors determining the success or failure of their projects. Strong stakeholder relationships were built over time-sometimes long before applying to 


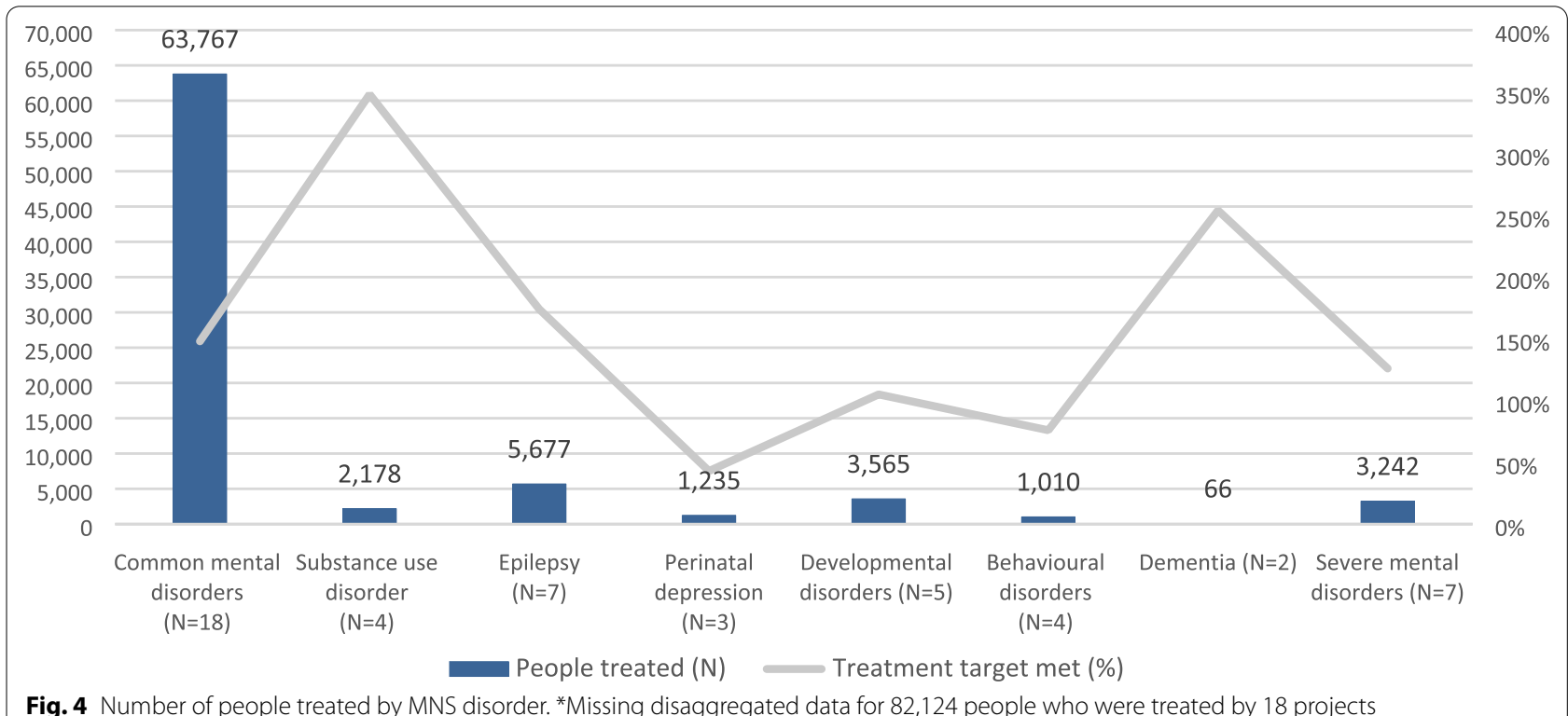

Fig. 4 Number of people treated by MNS disorder. *Missing disaggregated data for 82,124 people who were treated by 18 projects

GCC - and could be an important output in and of themselves, with long-term implications for sustainability [22].

The heterogeneity of the sample presented challenges. While there were common elements across most projects, small subgroup sample sizes made it difficult to make meaningful comparisons. In addition, the heterogeneity of the sample contributed to large amounts of missing data (i.e. when a component was not applicable to a specific project). Anecdotal evidence from grantees suggests reporting fatigue was also a factor. Routine reporting on health projects can prove burdensome, particularly in the absence of adequate information systems [39]. We suspect this may have been aggravated by the large amount of Core Metrics data requested, as well as the frequency of reporting required.

Large amounts of missing data, particularly on outcomes related to effectiveness, meant that it was not possible to carry out a QCA investigating which factors were sufficient or necessary to achieve impact across the full GCC portfolio. However, qualifying in advance what success at each step on the pathway should look like would also have been problematic. The variation we observed among project targets set by grantees suggests that these were not well-defined from the outset, an issue explored further in Qureshi et al. [23]. Importantly, the extent to which targets were achieved did not necessarily reflect the degree to which implementation was successful. For example, projects with high staff turnover may have been forced to recruit and train new staff, exceeding their training targets while still facing human resource shortages-as described in Endale et al. [21].
Finally, it is important to keep in mind the potential for reporting bias. Core Metrics data were extracted from reports that grantees submitted to their funder. It is also possible that grantees may have knowingly under- or over-estimated targets, either setting expectations low to mitigate risk of underperformance, or perhaps overpromising to improve the value-for-money proposition of their projects at proposal stage. This analysis is also skewed toward those projects that were able to successfully report outcome data during the GCC-funded timeframe. Projects that either never communicated belated results or never completed their evaluations may be more likely to have experienced significant challenges in delivering on other expectations, as well-painting a more optimistic picture of the portfolio's performance.

Box 1. Recommendations for the application of Theory of Change to portfolio-level evaluation

1. Engage grantees in designing reporting templates to ensure templates provide meaningful information and they do not cause reporting burden

2. Allocate resources for the development of relevant indicators for complex and difficult-to-capture components, e.g. context and stakeholder engagement

3. Allocate resources for the contextual validation of measurement tools, especially for less common disorders and settings where regional evidence is also lacking

4. Offer technical support to grantees to design and execute rigorous evaluations of their individual impact

5. Consider delays in obtaining final evaluation data when planning the timeline for portfolio-level evaluation

6. Use qualitative methods to complement and further explore quantitative findings, especially for complex and difficult-to-capture components 


\section{Conclusions}

Despite growing interest by funders, there is little prior evidence or experience of ToC-driven evaluation of funding portfolios documented in either the academic or grey literature. The application of $\mathrm{ToC}$ to Grand Challenges Canada's global mental health funding portfolio and the resulting Core Metrics framework offered an important opportunity to examine common aspects of diverse projects, which when coupled with qualitative exploration of complex themes and project-specific issues, helped to harness key learning from one of the largest investments in global mental health to-date. Future efforts to produce more definitive evaluations of global mental health funding portfolios should focus on supporting grantees to thoroughly monitor and evaluate their projects through to completion, recognising that the same challenges encountered in implementing mental health projects in low-resource settings are likely to also affect the quality and completeness of the data they generate. Supporting grantees to overcome these challenges will not only help funders to deliver impact through their funding portfolios, but also to measure their progress along the way.

\begin{abstract}
Abbreviations
AIDS: Acquired immunodeficiency syndrome; CAD: Canadian dollars; CQI: Continuous quality improvement; GCC: Grand Challenges Canada; HIV: Human immunodeficiency virus; IBM: International Business Machines Corporation; LMIC: Low- or middle-income country; LSHTM: London School of Hygiene and Tropical Medicine; MHIN: Mental Health Innovation Network; MNS: Mental, neurological and substance use; PRIME: PRogramme for Improving Mental hEalth care; PTSD: Post-traumatic stress disorder; QCA: Qualitative comparative analysis; RMAF: Results-based Management and Accountability Framework; SPSS: Statistical Package for the Social Sciences; ToC: Theory of Change; USD: United States dollars; WHO: World Health Organization.
\end{abstract}

\section{Acknowledgements}

We wish to acknowledge Tessa Robers, Agnes Becker and Vicky Nicholls, who assisted in carrying out interviews for the qualitative component of this research. We also thank Ricardo Araya for contributing to the design of the portfolio-level Theory of Change.

\section{Authors' contributions}

GME and GKR shared responsibilities for the write-up, with supervision from JE and MDS, who substantively revised the manuscript. LL and MDS were the lead researchers responsible for the design of the portfolio-level ToC, with support from SU and MR to harmonise the portfolio-level ToC with individual grantee ToCs. GLE, GME and SU shared responsibilities for the cleaning, analysis and interpretation of quantitative Core Metrics data. GKR conceptualised the qualitative component of this research, which was co-led by GLE, JM and LL. GLE, GKR, JM, LL, MR, OQ, SU and TE carried out qualitative interviews, which were analysed by JM, OQ and TE, who helped to triangulate quantitative and qualitative results. All authors read and approved the final manuscript.

\section{Funding}

The collection and analysis of data for this research were funded by GCC through the MHIN innovator support platform. GCC participated in the design of the portfolio-level Theory of Change and collected the quantitative Core Metrics data that were forwarded to MHIN for data cleaning and analysis. However, the funder played no role in the analysis or interpretation of data, the writing of the manuscript or the decision to submit for publication.

\section{Availability of data and materials}

The quantitative data that support the findings of this study are available from GCC, but restrictions apply to the availability of these data, which were used under license for the current study, and so are not publicly available. These data are however available from the authors upon reasonable request and with permission of GCC.

The qualitative data generated during the current study are not publicly available due to the sensitivity of discussions surrounding the performance of grantees' projects but are available from the corresponding author upon reasonable request.

\section{Ethics approval and consent to participate}

Ethical approval was granted by the London School of Hygiene and Tropical Medicine's Research Ethics Committee (reference numbers 7746 and 9945). Participants in semi-structured interviews were required to provide written informed consent prior to the start of the interview.

\section{Consent for publication}

Not applicable.

\section{Competing interests}

The authors have previously received GCC funding, through the MHIN innovator support platform (GKR, GLE, GME, JE, LL, MDS, MR, OQ, SU, TE) and/or through a GCC grant for a project included in this dataset $(J M, O Q)$.

\section{Author details}

${ }^{1}$ Health Service and Population Research Department, Institute of Psychiatry, Psychology and Neuroscience, King's College London, 16 De Crespigny Park, Camberwell, London SE5 8AB, UK. ${ }^{2}$ ESRC Centre for Society and Mental Health, King's College London, London, UK. ${ }^{3}$ Department of Population Health, London School of Hygiene and Tropical Medicine, London, UK. ${ }^{4}$ Centre for Brain and Cognitive Development, Department of Psychological Sciences, Birkbeck College, University of London, London, UK. ${ }^{5}$ Independent Researcher, Minneapolis, MN, USA. ${ }^{6}$ Independent Researcher, London, UK.

${ }^{7}$ Department of Psychiatry, Faculty of Medicine, University of British Columbia, Vancouver, BC, Canada. ${ }^{8}$ Department of Counselling and Clinical Psychology, Teachers College, Columbia University, New York, NY, USA. ${ }^{9}$ Health Improvement Directorate, Public Health England, London, UK. ${ }^{10}$ CBM Global, Cambridge, UK. ${ }^{11}$ Department of Population Health, Wellcome Trust, London, UK.

\section{Appendix 1}

See Fig. 5. 
GRAND CHALLENGES CANADA | INTEGRATED INNOVATIONS IN GLOBAL MENTAL HEALTH ROUND ONE | PROGRAM LEVEL THEORY OF CHANGE | VO8 JAN 2015

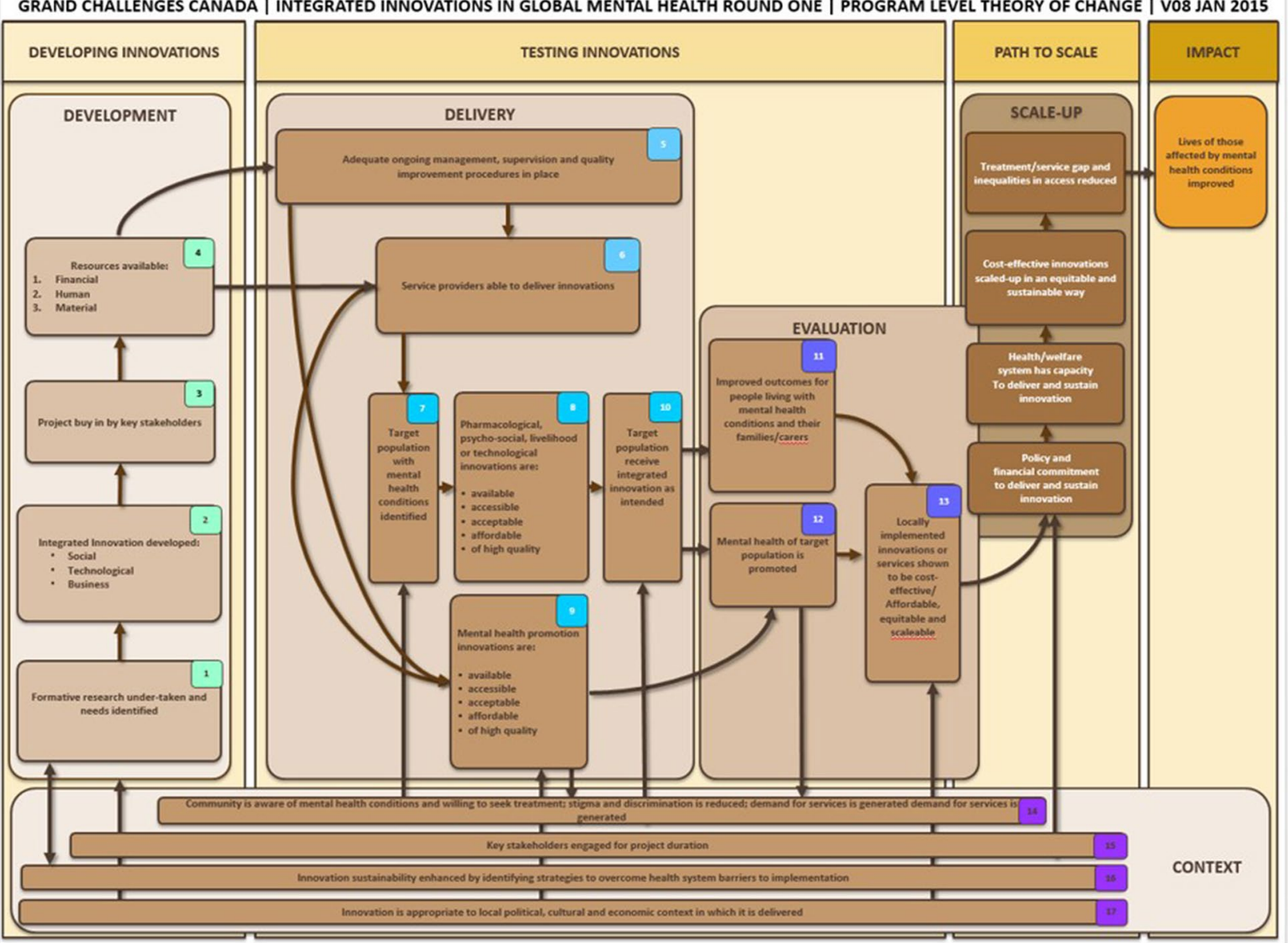

Received: 29 September 2020 Accepted: 15 February 2021 Published online: 27 February 2021

\section{References}

1. Patel V, Saxena S, Lund C, Thornicroft G, Baingana F, Bolton P, et al. The Lancet Commission on global mental health and sustainable development. Lancet. 2018:392(10157):1553-98.

2. World Health Organization. Mental Health Atlas 2017. Geneva: World Health Organization; 2018.

3. Charlson FJ, Dieleman J, Singh L, Whiteford H. Donor financing of global mental health, 1995-2015: an assessment of trends, channels, and alignment with the disease burden. PLOS ONE. 2017:12:1.

4. Vigo D, Thornicroft G, Atun R. Estimating the true global burden of mental illness. Lancet Psychiatry. 2016:3(2):171-8.

5. Lancet Global Mental Health Group. Scale up services for mental disorders: a call for action. Lancet. 2007:370(9594):1241-52.

6. Economist T. Most mental-health problems are untreated. The Economist: Trained laypeople can help; 2019.

7. Department of Health \& Social Care. 2018 Global Ministerial Mental Health Summit: Report and Declaration on Achieving Equality for Mental Health in the 21st Century. UK: Department of Health \& Social Care; 2019.
8. Kleinman A, Estrin GL, Usmani S, Chisholm D, Marquez PV, Evans TG, et al. Time for mental health to come out of the shadows. Lancet. 2016;387(10035):2274.

9. London School of Hygiene and Tropical Medicine. Time to act - 'Friendship Bench'founder joins HRH Duke of Cambridge on mental health panel at Davos London, UK2019. https://www.lshtm.ac.uk/newsevents /news/2019/time-act-friendship-bench-founder-joins-hrh-duke-cambr idge-mental-health-panel.

10. Liese BH, Gribble RS, Wickremsinhe MN. International funding for mental health: a review of the last decade. International health. 2019;11(5):361-9.

11. Academy of Medical Sciences and InterAcademy Partnership for Health. Challenges and priorities for global mental health in the Sustainable Development Goals (SDG) era. In: Workshop Report 28-29 June 2018. London: The Academy of Medical Sciences; 2018.

12. Collins PY, Patel V, Joestl SS, March D, Insel TR, Daar AS, et al. Grand challenges in global mental health. Nature. 2011:475(7354):27.

13. MacArthur $G$, editor Challenges and priorities for global mental health research in low-and middle-income countries. Symposium report. Challenges and priorities for global mental health research in low-and middle-income countries Symposium report; 2008: Academy of Medical Sciences.

14. Tol WA, Patel V, Tomlinson M, Baingana F, Galappatti A, Panter-Brick C, et al. Research priorities for mental health and psychosocial support in humanitarian settings. PLoS Med. 2011;8:9 
15. Breuer E, De Silva M, Lund C. Theory of change for complex mental health interventions: 10 lessons from the programme for improving mental healthcare. Global Mental Health. 2018;5:9.

16. Jackson ET. Interrogating the theory of change: evaluating impact investing where it matters most. J Sustain Fin Investment. 2013;3(2):95-110.

17. Plimmer D, Kail A. Theory of change for funders: Planning to make a difference. London: New Philantropy Capital; 2014.

18. Weiss $\mathrm{CH}$. Nothing as practical as good theory: Exploring theory-based evaluation for comprehensive community initiatives for children and families. New Approaches Eval Community Init. 1995;1:65-92.

19. Adams O, Guimaraes L, Atherton F, Franzen S. Development Innovation Fund - Health: Summative Evaluation Report. Oxford: Oxford Policy Management; 2015.

20. Grand Challenges Canada. Evaluations Canadan.d. https://www.grand challenges.ca/who-we-are/evaluations/.

21. Endale T, Qureshi O, Ryan GK, Esponda GM, Verhey R, Eaton J, et al. Barriers and drivers to capacity-building in global mental health projects. Int J Ment Health Syst. 2020;14(1):1-12.

22. Murphy J, Qureshi O, Endale T, Esponda GM, Pathare S, Eaton J, et al. Barriers and drivers to stakeholder engagement in global mental health projects. [Preprint]. 2020.

23. Qureshi O, Endale T, Ryan G, Miguel-Esponda G, Iyer SN, Eaton J, et al. Barriers and drivers to service delivery in global mental health projects. Int Ment Health Syst. 2021;15(1):1-13.

24. Chibanda D, Verhey R, Munetsi E, Cowan FM, Lund C. Using a theory driven approach to develop and evaluate a complex mental health intervention: the friendship bench project in Zimbabwe. Int J Ment Health Syst. 2016;10(1):16.

25. De Silva MJ, Breuer E, Lee L, Asher L, Chowdhary N, Lund C, et al. Theory of change: a theory-driven approach to enhance the Medical Research Council's framework for complex interventions. Trials. 2014;15(1):267

26. Patton MQ. Utilization-focused evaluation. New York: Sage publications: 2008.

27. Lund C, Tomlinson M, De Silva M, Fekadu A, Shidhaye R, Jordans M, et al. PRIME: a programme to reduce the treatment gap for mental disorders in five low-and middle-income countries. PLoS Med. 2012;9:12.

28. Breuer E, Subba P, Luitel N, Jordans M, De Silva M, Marchal B, et al. Using qualitative comparative analysis and theory of change to unravel the effects of a mental health intervention on service utilisation in Nepal. BMJ Global Health. 2018;3:6

29. Vogel I. Review of the use of 'Theory of Change'in international development. London: DFID; 2012.

30. De Silva MJ, Ryan G. Global mental health in 2015: $95 \%$ implementation. The Lancet Psychiatry. 2016;3(1):15-7.

31. Dickson K, Bangpan M. What are the barriers to, and facilitators of, implementing and receiving MHPSS programmes delivered to populations affected by humanitarian emergencies? A qualitative evidence synthesis. Global Mental Health. 2018;5:89.

32. Zechmeister I, Kilian R, McDaid D. Is it worth investing in mental health promotion and prevention of mental illness? A systematic review of the evidence from economic evaluations. BMC public health. 2008;8(1):20.

33. Mechanic D. Is the prevalence of mental disorders a good measure of the need for services? Health Aff. 2003;22(5):8-20.

34. Baxter AJ, Patton G, Scott KM, Degenhardt L, Whiteford HA. Global epidemiology of mental disorders: what are we missing? PLOS ONE. 2013;8(6):e65514

35. Roberts T, Esponda GM, Krupchanka D, Shidhaye R, Patel V, Rathod S. Factors associated with health service utilisation for common mental disorders: a systematic review. BMC Psychiatry. 2018;18(1):262.

36. Wang PS, Aguilar-Gaxiola S, Alonso J, Angermeyer MC, Borges G, Bromet EJ, et al. Use of mental health services for anxiety, mood, and substance disorders in 17 countries in the WHO world mental health surveys. The Lancet. 2007;370(9590):841-50.

37. Ali G-C, Ryan G, De Silva MJ. Validated Screening Tools for Common Mental Disorders in Low and Middle Income Countries: A Systematic Review. PLoS ONE. 2016;11(6):e0156939.

38. Silver K. Canada GC, editor. 2014. https://www.grandchallenges.ca/2014/ theories-of-change-and-common-metrics-drive-search-for-big-impac t-in-global-health/.

39. Dixon-Woods M, McNicol S, Martin G. Ten challenges in improving quality in healthcare: lessons from the Health Foundation's programme evaluations and relevant literature. BMJ Qual Saf. 2012;21(10):876-84.

\section{Publisher's Note}

Springer Nature remains neutral with regard to jurisdictional claims in published maps and institutional affiliations.
Ready to submit your research? Choose BMC and benefit from:

- fast, convenient online submission

- thorough peer review by experienced researchers in your field

- rapid publication on acceptance

- support for research data, including large and complex data types

- gold Open Access which fosters wider collaboration and increased citations

- maximum visibility for your research: over $100 \mathrm{M}$ website views per year

At BMC, research is always in progress.

Learn more biomedcentral.com/submissions 